\title{
BMJ Open Prevalence and correlates of sleep disturbance and depressive symptoms among Chinese adolescents: a cross-sectional survey study
}

\author{
Lan Guo, ${ }^{1}$ Jianxiong Deng, ${ }^{2}$ Yuan He, ${ }^{1}$ Xueqing Deng, ${ }^{1}$ Jinghui Huang, ${ }^{2}$ \\ Guoliang Huang, ${ }^{2}$ Xue Gao, ${ }^{1}$ Ciyong Lu ${ }^{1}$
}

To cite: Guo L, Deng J, He Y, et al. Prevalence and correlates of sleep disturbance and depressive symptoms among Chinese adolescents:

a cross-sectional survey study. BMJ Open 2014;4: e005517. doi:10.1136/ bmjopen-2014-005517

- Prepublication history for this paper is available online. To view these files please visit the journal online (http://dx.doi.org/10.1136/ bmjopen-2014-005517)

LG, JXD and YH contributed equally.

Received 21 April 2014 Revised 1 July 2014 Accepted 8 July 2014

\section{CrossMark}

For numbered affiliations see end of article.

Correspondence to

Dr Ciyong Lu;

luciyong@mail.sysu.edu.cn

\section{ABSTRACT}

Study objective: To investigate the prevalence and the correlates of sleep disturbance and depressive symptoms among Chinese adolescents and to examine the association between the two problems.

Design: Cross-sectional survey.

Participants: A total of 3186 school students in grades 7-12 were sampled from the schools in Guangdong. A stratified-cluster random-sampling strategy was used to select the schools.

Main outcome measures: A self-administered questionnaire was used. The Pittsburgh Sleep Quality index (PSQI) was used to assess the occurrence of sleep disturbance, and the Center for Epidemiology Scale for Depression (CES-D) was used to identify whether individuals had depressive symptoms.

Results: The mean PSQI global score was $8.7( \pm 2.4)$ points, and $39.6 \%$ of the total sample had sleep disturbance. The mean CES-D score of students was $15.2( \pm 9.4)$ points, and $6.4 \%$ of the students had depressive symptoms. Additionally, girls and older adolescents were more likely to suffer from sleep disturbance, and the students who had depressive symptoms were 2.47 (95\% $\mathrm{Cl} 1.61$ to 3.79) times more likely to suffer from sleep disturbance. Factors that were correlated with sleep disturbance and depressive symptoms were having a poor relationship with teachers, feeling lonely, suicide ideation and having run away from home.

Conclusions: Sleep disturbance was determined to be more prevalent among Chinese adolescents with depressive symptoms. Sleep disturbance and depressive symptoms were associated with each other, while school factors, family factors and psychosocial adjustment were comprehensively correlated with both.

\section{INTRODUCTION}

Adolescence is often described as occurring between 13 and 18 years of age, which is roughly the period of high school for much of the world. ${ }^{1}$ Sleep plays a very important role in the development of adolescents; it

\section{Strengths and limitations of this study}

- There has been a lack of epidemiological research about sleep disturbance and depressive symptoms among Chinese adolescents.

- The results of the study show that sleep disturbance is more prevalent among Chinese adolescents who have depressive symptoms.

- There is a link between sleep disturbance and depressive symptoms.

- The study demonstrates that an adolescent's demographic, family, school and psychosocial factors influence sleep disturbance and depressive symptoms.

- The sample size limits the conclusions that can be drawn from the multivariate analysis; however, quantifying correlates of sleep disturbance and depressive symptoms was a secondary objective of the study.

impacts physical growth and behaviour, and affects the mental health status. ${ }^{2}$ Studies in western countries have estimated that a large proportion (25-40\%) of adolescents have sleep disturbance, ${ }^{3-5}$ and a report from China in 2000 revealed that $16.9 \%$ of the sample was troubled with sleep disturbance. ${ }^{6}$ In total, adolescents' sleep disturbance has been a major international public health problem, and China is no exception, although the prevalence of Chinese adolescents with sleep disturbance has been a little lower than western countries.

Depressive symptoms are a type of mental disorder, and the link between sleep disturbance and depressive symptoms in adulthood is well established. ${ }^{7}$ For instance, women suffering from sleep disturbances have lower self-rated health and more physical and mental health symptoms, such as depressive symptoms. ${ }^{8}$ In contrast, a limited number of studies (especially epidemiological studies) have addressed the link between sleep 
disturbance and depressive symptoms among adolescents, and the link is not uniform. One study in the USA has found that adolescents with sleep disturbance are more likely to develop and maintain depressive symptoms than adolescents without sleep disturbance, ${ }^{9}$ but one study found that there did not appear to be a strong association between sleep disturbance and depressive symptoms in adolescents. ${ }^{10}$ Additionally, many researchers in the USA have reported that sleep disturbance can be a sign of depressive symptoms, and depressive symptoms can likewise be a sign of sleep disturbance. ${ }^{11} \mathrm{Xu}$ et $a l^{\mathrm{s}}{ }^{12}$ research in China also demonstrated that sleep disturbance and depressive symptoms are closely related, and insufficient sleep may result in depressive symptoms. The recent increase in interest in the link between sleep disturbance and depressive symptoms in adolescents is warranted.

Sleep disturbance and depressive symptoms among adolescents are not only influenced by each other but also by demographics, family, school and social factors. ${ }^{13}$ Several variables have been associated with sleep disturbance and depressive symptoms. Previous studies have differing results about the characteristics of sleep disturbances between the two genders. Boys in Hong Kong were more likely to be troubled by sleep disturbance than girls, ${ }^{14}$ but most of the studies from other countries found that girls were more likely to report sleep disturbances than boys. ${ }^{15}{ }^{16}$ Such inconsistencies may be attributed to differences in the sample and place, which suggested further research with larger samples is warranted. Additionally, Liu $e t a l \mathrm{~s}^{17}$ study in China indicated that the prevalence of sleep disturbance varies with age and grade level among adolescents, and adolescents from incomplete families were more likely to have sleep disturbance compared with their peers. Furthermore, parents' sleep patterns and psychological functions were associated with adolescents' sleep in Iran. ${ }^{18}$ In addition, school environment is important for sleep quality and mental status of adolescents. ${ }^{19}$ Li's research has demonstrated that poor classmate relation predicted a high level of sleep disturbance and depressive symptoms among Chinese adolescents. One striking difference between Chinese and US adolescents is the salience of school and academic achievements relative to other concerns, and Chinese adolescents care more about academic achievements. ${ }^{20}$ Overall, although we conclude that sleep disturbance and depressive symptoms are a universal phenomenon among adolescents, it is clear that there are cultural variations in their prevalence and the way sleep disturbance or depressive symptoms relate to other factors. ${ }^{21}$ Most previous studies, however, have been carried out in western or developed countries, and only a handful of studies have been conducted in developing countries. There is also a paucity of studies on family status (ie, living arrangement and family economic status), school dynamics (ie, relationships with classmates or teachers) and personal psychosocial adjustment (ie, feeling lonely and attempting suicide) in the Chinese cultural context. Therefore, we conducted this large-scale cross-sectional study in China to estimate the prevalence of sleep disturbance and depressive symptoms; to comprehensively examine the potentially contributing factors to sleep disturbance and depressive symptoms among demographics, school, family and psychosocial health; and to discuss the link between sleep disturbance and depressive symptoms.

The following three hypotheses were formulated. First, following the results of previous studies, ${ }^{6}{ }^{19}$ we hypothesised that sleep disturbance or depressive symptoms are a major public health problem nationwide among Chinese adolescents. Second, consistent with previous findings, ${ }^{15}$ 18-20 we expected that demographics, family, school and psychosocial factors would be related to sleep disturbance or depressive symptoms among Chinese adolescents. Third, in line with prior research linking sleep disturbance and depressive symptoms, ${ }^{9} 12$ we expected sleep disturbance to be a risk factor for depressive symptoms among Chinese adolescents, and vice versa.

\section{METHODS}

\section{Study design and participants}

This cross-sectional study was based on a province-wide sample to estimate the prevalence of sleep disturbance and depressive symptoms and to examine the relationship between potentially influential factors and their involvement in sleep disturbance and depressive symptoms among Chinese adolescents. The participants were high school students from Guangdong, China. Guangdong is known as an immigrant province, with more than half of the population migrating from other provinces; therefore, the sample from Guangdong has a certain degree of representativeness. First, the schools were divided into three categories: junior high schools (grades 7-9), senior high schools (grades 10-12) and vocational schools (grades 7-12). A stratified-cluster random-sampling method was used to randomly select participants among the three types of schools. Six junior high schools, four senior high schools and two vocational schools were selected. Next, two classes were randomly selected from each grade in these schools. All available students within the grade were surveyed; those not surveyed were absent or refused to participate and consisted of less than $1 \%$ of the student population. All the participants were fully informed of the purpose of the survey and were invited to participate voluntarily. Written consent letters were obtained from the school, each participating student and one of the student's parents. A rigorously anonymous method for collection of the self-report questionnaires was guaranteed. The questionnaires were administered by research assistants in the classrooms without the presence of the teachers. It is important to stress that we used a self-designed questionnaire whose questions were based on an instrument proposed by the WHO and adapted to the realities 
of China, and the findings of a number of investigations indicate that such data can be extremely useful. ${ }^{122}$

\section{Measures}

\section{Independent variables}

Sociodemographic variables: Age, grade and gender.

Family factors: Living arrangement, family economic status, family relationship and parental caring. Living arrangements were assessed by asking who lived in the student's primary home. Family economic status was measured by asking the student's perception of their family's current economic status (rated from below average to above average). Family relationships were assessed by asking the students, with the responses coded on a 3-point scale ranging from below average to above average. Parental caring was assessed by asking, "Are you satisfied with the love you receive from your father, mother, or both of them, based on a 4-point scale from dissatisfaction to satisfaction?"

School factors: Classmate relations and teacherclassmate relations were also assessed based on the student's self-rating about their relationships with classmates and teachers, ranging from poor to good. Academic achievements and academic pressure were captured by a single item asking about a personal appraisal of students' performances or pressure relative to that of their classmates (responses were coded as 'above average', 'average' and below 'average').

Psychosocial adjustment: Feeling lonely was assessed by asking, 'During the past 12 months, how often did you feel lonely per week?' Response options ranged from 1 (never) to 4 (over 4 days). Suicide-ideation status was based on whether a participant had endorsed thoughts of suicide over the past year. Suicide-attempt status was based on attempts made over the past year, with one or more attempts indicating endorsement. A student's attempt to hurt themselves was assessed by asking, 'During the past 12 months, did you ever hurt yourself on purpose?' Responses were categorised into four groups: never, considered, planned and attempted. Running away from home was assessed by asking, 'During the past 12 months, did you run away from home without your parents' permission for more than $24 \mathrm{~h}$ ?' Response options were (1) never, (2) considered, (3) attempted or (4) have run away from home one time or more. Habits of sleeping after lunch were assessed based on the student's self-rating about their habit, ranging from poor to good.

\section{Dependent variables}

We used the Chinese Pittsburgh Sleep Quality Index (CPSQI) to assess sleep quality and disturbances over a 1-month time interval; the sum of the scores for these seven components yields one global score with a range of 0-21 points in which higher scores indicate worse sleep quality. ${ }^{22}{ }^{23}$ The CPSQI was translated into Mandarin Chinese to better correspond to the meaning of the original items in PSQI, and it is valid, reliable and commonly used. In China, a PSQI global score of above
7 points indicates poor sleep quality collectively known as sleep disturbance, a higher score indicates a greater reduction in sleep quality. ${ }^{22}$

The Center for Epidemiology Scale for Depression (CES-D) in Chinese was used to identify whether individuals had depressive symptoms. The respondents were asked to rate the frequency, over the past week, of 20 depressive symptoms by choosing 1 of 4 response options ranging from 'rarely or none of the time' to 'most or all of the time'.24 The Chinese version of this scale has been validated, ${ }^{25-27}$ and extensively utilised in Chinese studies. ${ }^{28}$ The score ranges from 0 to 60 , and the original recommended cut-off point for having depressive symptoms was 16 points (corresponding to the 80th centiles) by the founder of the CES-D in $1977 .^{29}$ We adopted the 80th centile as the cut-off (a score greater than 28 indicating 'having depressive symptoms'), and the area under the ROC curve was 0.78. For the Center for Epidemiological Studies Depression Scale (CES-D) survey, those who failed to answer at least 17 of the 20 items were eliminated.

\section{Statistical analysis}

All data were entered by two investigators independently using EpiData 3.1, and the statistical analyses were conducted using SPSS V.21.0 and SAS V.9.2. Descriptive analyses were used to describe demographic characteristics and the prevalence of sleep disturbances and depressive symptoms among adolescents. Categorical and continuous data were reported in the form of proportions and means (SD). $\chi^{2}$ Tests were used to test the difference between the categorical variables referred to above. Multivariate logistic regression models included the significant variables that had been tested by univariate analyses or widely reported in the literature; these were used to screen for the risk factors for sleep disturbance/ depressive symptoms according to the ORs and95\% CIs. An OR $>1$ with $\mathrm{p}<0.05$ was reported as a risk factor. Considering that our study used a multistage sampling, students were grouped into classes; therefore, differences might not segregate independently. Thus, multilevel analyses (the generalised linear mixed effects models adopting the GLMMIX procedure in SAS) in which classes were treated as clusters were adopted in the multivariate logistic regression analyses. All statistical tests were two-sided, with a $p$ value less than 0.05 considered significant.

\section{RESULTS}

A total of 3508 students were invited to participate, and 3485 students' questionnaires were completed and qualified for our survey; the response rate was $95.2 \%$. After excluding students who were not 13-18 years old, we analysed 3186 students' data.

\section{Demographic information}

A total of 3186 participants were involved in this analysis. Table 1 provides the basic demographic information for 


\begin{tabular}{|c|c|}
\hline Variable & Number (\%) \\
\hline Total & $3186(100.0)$ \\
\hline \multicolumn{2}{|l|}{ Gender } \\
\hline Male & $1700(53.4)$ \\
\hline Female & $1486(46.6)$ \\
\hline \multicolumn{2}{|l|}{ Age (years) } \\
\hline $13-14$ & $420(13.2)$ \\
\hline $15-16$ & $1687(53.0)$ \\
\hline $17-18$ & 1079 (33.9) \\
\hline \multicolumn{2}{|l|}{ Grade } \\
\hline 7th-9th & $1686(52.9)$ \\
\hline 10th-12th & $1500(47.1)$ \\
\hline \multicolumn{2}{|l|}{ Living arrangement } \\
\hline Two biological parents & $2836(89.0)$ \\
\hline Only father or mother & $149(4.7)$ \\
\hline Others & $201(6.3)$ \\
\hline \multicolumn{2}{|l|}{ Family economic status } \\
\hline Above average & $975(30.6)$ \\
\hline Average & $1942(61.0)$ \\
\hline Below average & $269(8.4)$ \\
\hline \multicolumn{2}{|l|}{ Family relationship } \\
\hline Above average & $2501(78.5)$ \\
\hline Average & $502(15.8)$ \\
\hline Below average & $183(5.7)$ \\
\hline \multicolumn{2}{|l|}{ Parental caring } \\
\hline Satisfied with father or mother & $545(17.1)$ \\
\hline Satisfied with both of them & $2471(77.6)$ \\
\hline Dissatisfied with both of them & $170(5.3)$ \\
\hline \multicolumn{2}{|l|}{ Academic achievement } \\
\hline Above average & $1361(42.7)$ \\
\hline Average & 932 (29.3) \\
\hline Below average & $893(28.0)$ \\
\hline \multicolumn{2}{|l|}{ Academic pressure } \\
\hline Above average & $1344(42.2)$ \\
\hline Average & 1376 (43.2) \\
\hline Below average & 466 (14.4) \\
\hline \multicolumn{2}{|l|}{ Relationship with teachers } \\
\hline Good & $1552(48.7)$ \\
\hline Average & $1408(44.2)$ \\
\hline Poor & $226(7.1)$ \\
\hline \multicolumn{2}{|l|}{ Relationship with classmates } \\
\hline Good & $2220(69.7)$ \\
\hline Average & $846(26.6)$ \\
\hline Poor & $120(3.8)$ \\
\hline \multicolumn{2}{|l|}{ Feel lonely } \\
\hline Less than 1 day/week & $1733(54.4)$ \\
\hline 1 to 4 days/week & $1073(33.7)$ \\
\hline More than 4 days/week & $380(11.9)$ \\
\hline \multicolumn{2}{|l|}{ Suicide ideation } \\
\hline Never & 2589 (81.3) \\
\hline Occasionally (1-2 times/year) & 391 (12.3) \\
\hline Sometimes (3-6 times/year) & $75(2.4)$ \\
\hline Often (over 6 times/year) & $131(4.1)$ \\
\hline \multicolumn{2}{|l|}{ Suicide attempt } \\
\hline Never & $3083(95.8)$ \\
\hline Occasionally (1-2 times/year) & $81(2.5)$ \\
\hline Sometimes (3-6 times/year) & $14(0.4)$ \\
\hline Often (over 6 times/year) & $38(1.2)$ \\
\hline
\end{tabular}

\begin{tabular}{lc} 
Table 1 Continued & \\
\hline Variable & Number (\%) \\
\hline Hurt themselves on purpose & \\
$\quad$ Never & $2807(88.1)$ \\
Occasionally (1-2 times/year) & $269(8.4)$ \\
Sometimes (3-6 times/year) & $61(1.9)$ \\
Often (over 6 times/year) & $49(1.5)$ \\
Running away from home & \\
Never & $2262(71.0)$ \\
Considered & $815(25.6)$ \\
Planned & $48(1.5)$ \\
Attempted & $61(1.9)$ \\
Habit of sleeping after lunch & $308(9.7)$ \\
Never & $1598(50.2)$ \\
Occasionally (1-4 times/week) & $1280(40.2)$ \\
Often (over 4 times/week) & \\
\hline
\end{tabular}

the sample involved in this study. The proportion of boys was $53.4 \%$, and the male-to-female ratio was approximately 1.2:1. The students ranged in age from 13 to 18 years old, and the mean age of the students was $15.6( \pm 1.6)$ years. The students who never slept after lunch accounted for $9.7 \%$. The grade 7-9 group of students represented $52.9 \%$ of the sample. Regarding the family factors, a total of $89 \%$ of students lived with both biological parents, whereas $4.7 \%$ lived in single-parent families. A total of $15.8 \%$ of students thought of their family relationships as average, and $77.6 \%$ of students were satisfied with both of their parents' love. A subset of students $(30.6 \%)$ reported that their current economic status was above average, whereas $8.4 \%$ reported that their economic status was below average. Regarding school factors, $28 \%$ of students rated their academic achievement as below average, and $42.2 \%$ of the students thought their academic pressure was above average. A total of $7.1 \%$ of participants reported poor relationships with their teachers and $3.8 \%$ had poor relations with their classmates. Regarding the psychosocial factors, $11.9 \%$ of students felt lonely more than 4 days per week. A total of $4.1 \%$ of students often had suicide ideation, and $1.2 \%$ of students had attempted suicide often. In addition, $1.5 \%$ of participants often hurt themselves on purpose, and $1.9 \%$ of participants had run away from home more than once.

\section{Univariate analysis for sleep disturbance and depressive symptoms}

The mean PSQI global score was $8.7( \pm 2.4)$ points $(8.6$ $( \pm 2.5)$ points among boys, $8.6( \pm 2.4)$ points among girls), and $39.6 \%$ of the total sample was classified as having sleep disturbances (global score higher than 8 points). In addition, $6.4 \%$ of the students had depressive symptoms, according the CES-D. The mean CES-D score of students was $15.2( \pm 9.4)$ points $(14.6( \pm 9.1)$ points among boys, $15.6( \pm 8.8)$ points among girls $)$. 
There were no gender differences in the PSQI global scores or the CES-D scores. ( $p>0.05$ )

As shown in table 2, without adjustment for other variables, sleep disturbances and depressive groups were correlated with gender, family economic status, family relationships, parental caring, academic pressure, relationships with classmates, feeling lonely, suicide ideation, suicide attempts, hurting themselves on purpose and having run away from home. Only age, grade, relationship with teachers and having depressive symptoms were significantly correlated with having a sleep disturbance, while only living arrangements and having sleep disturbances were significantly correlated with having depressive symptoms.

\section{Multilevel logistic regression analysis: sleep disturbance}

The final logistic regression model for sleep disturbance is presented in table 3. Ten of the original variables remained in the final model: gender, age, habit of sleeping after lunch, family relationships, academic pressure, relationships with teachers, feeling lonely, suicide ideation, running away from home and depressive symptoms. The results revealed that girls, the 15-16 and the 1718-year age group were all more likely to suffer from sleep disturbance. Taking occasional naps after lunch was a risk factor for sleep disturbance compared with the group that never napped after lunch (adjusted $\mathrm{OR}=1.68,95 \%$ CI 1.27 to 2.22). Adolescents with below-average family relationships $(\mathrm{AOR}=1.54,95 \% \mathrm{CI}$ 1.06 to 2.26) had a slightly higher probability of sleep disturbance. Likewise, students with poor relationships with teachers (AOR=1.26, 95\% CI 1.19 to 1.77 ) were more troubled with sleep disturbances. In addition, students feeling lonely $1-4$ days a week $(\mathrm{AOR}=1.64,95 \% \mathrm{CI}$ 1.39 to 1.94 ) or over 4 days a week ( $\mathrm{AOR}=2.22,95 \%$ CI 1.70 to 2.89 ) had a higher probability of sleep disturbances compared with those never feeling lonely. Having suicide ideations occasionally or sometimes was a risk factor for sleep disturbance, and students who considered running away from home (AOR $=1.76,95 \%$ CI 1.46 to 2.13 ) or attempted running away from home $(\mathrm{OR}=2.59,95 \%$ CI 1.38 to 4.88$)$ were also more likely to have a sleep disturbance compared with students who had never considered running away from home. Finally, students who had depressive symptoms were $2.47(95 \%$ CI 1.61 to3.79) times more likely to suffer from sleep disturbance than those who did not. Notably, students with average academic pressure $(\mathrm{AOR}=0.80,95 \%$ CI 0.65 to 0.99 ) or below-average academic pressure $(\mathrm{AOR}=0.41$, $95 \%$ CI 0.33 to 0.51 ) compared with the above-average academic pressure group were less likely to be troubled by sleep disturbance.

\section{Multilevel logistic regression analysis: depressive symptoms}

The final model for depressive symptoms in table 4 showed many correlations. Adolescents with a below-average family relationship (AOR=1.97, 95\% CI
1.24 to 3.15$)$ were more likely to have depressive symptoms. Having average relationships with classmates $(\mathrm{AOR}=2.82,95 \%$ CI 1.62 to 4.90$)$ or poor relationships with classmates (AOR=1.60, 95\% CI 1.14 to 2.25) was a risk factor for having depressive symptoms. Students who felt lonely $1-4$ days a week $(\mathrm{AOR}=2.67,95 \%$ CI 1.75 to 4.07$)$ or over 4 days a week ( $\mathrm{AOR}=4.24,95 \%$ CI 2.65 to 6.80 ) also had a higher probability of having depressive symptoms. Likewise, students occasionally, sometimes or often having suicide ideation had a higher probability of having depressive symptoms. Considering running away from home (AOR=1.71, 95\% CI 1.20 to 2.44) was also a risk factor for depressive symptoms compared with students who never considered running away from home. Students with sleep disturbance were also more likely to have depressive symptoms $(\mathrm{AOR}=2.52$, 95\% CI 1.64 to 3.86 ).

\section{DISCUSSION}

In this study, we found that sleep disturbance was not rare among Chinese adolescents, with a prevalence of $39.6 \%$. Similar studies have reported that the prevalence of sleep disturbance in children and adolescents ranges from $66 \%$ to $90 \% .^{30}$ A report from China in 2000 revealed that $16.9 \%$ of the sample was troubled with sleep disturbance, ${ }^{6}$ while a report from China in 1987 reported a prevalence of $14.9 \% .^{31}$ This study also agrees with the results from a western report in which $43 \%$ of children experienced sleep disturbance. ${ }^{32}$ The considerable variation in the prevalence of sleep disturbances may be due to the different time periods, different target populations and different methodological definitions of sleep disturbances. Adolescent sleep disturbance has been recognised as a major international public health problem, and China is no exception, although the prevalence of Chinese adolescents with sleep disturbance was a little lower than western countries.

In addition, our results indicate that girls were more likely to suffer from sleep disturbance, which agrees with the previous study from Anhui province and Hong Kong in China. ${ }^{12}{ }^{14}$ In this study, older age was more often associated with sleep disturbance compared with the younger group, which is in line with a previous study from China that reported that older age was associated with more sleep problems. ${ }^{6}$

Additionally, multivariate logistic regression analyses performed to control for confounding factors and to determine the main correlates of sleep disturbance showed that poor family relationships, poor relationships with teachers, feeling lonely, suicide ideation, running away from home and depressive symptoms were correlated with sleep disturbance. These findings are in accordance with the results of many previous studies. For example, a study from Shandong province of China in 2000 also reported that poor marital relations of parents, poor family economic status, poor child-parent and peer relations, poor school achievement and social 
Table 2 Univariate $\chi^{2}$ analysis for sleep disturbance and depressive symptoms, $\mathrm{n}(\%)$

\begin{tabular}{|c|c|c|c|}
\hline Variable & Total & With sleep disturbance & With depressive symptoms \\
\hline Total & $3186(100.0)$ & $1261(100.0)$ & $205(100.0)$ \\
\hline \multicolumn{4}{|l|}{ Gender* } \\
\hline Male & $1700(53.4)$ & $729(57.8)$ & $92(44.9)$ \\
\hline Female & $1486(46.6)$ & $532(42.2)$ & $113(55.1)$ \\
\hline \multicolumn{4}{|l|}{ Age (years) $\dagger$} \\
\hline $13-14$ & $420(13.2)$ & $240(19.0)$ & $22(10.7)$ \\
\hline $15-16$ & $1687(53.0)$ & 667 (52.9) & $111(54.1)$ \\
\hline $17-18$ & 1079 (33.9) & $354(28.1)$ & $72(35.1)$ \\
\hline \multicolumn{4}{|l|}{ Grade† } \\
\hline 7th-9th & $1686(52.9)$ & $740(58.7)$ & $108(52.7)$ \\
\hline 10th-12th & $1500(47.1)$ & $521(41.3)$ & 97 (47.3) \\
\hline \multicolumn{4}{|l|}{ Living arrangement } \\
\hline Two biological parents & $2836(89.0)$ & $1125(89.2)$ & $169(82.4)$ \\
\hline Only father or mother & $149(4.7)$ & $51(4.0)$ & $16(7.8)$ \\
\hline Others & $201(6.3)$ & $85(6.7)$ & $20(9.8)$ \\
\hline \multicolumn{4}{|l|}{ Family economic status* } \\
\hline Above average & $975(30.6)$ & $437(34.7)$ & $45(22.0)$ \\
\hline Average & $1942(61.0)$ & $738(58.5)$ & $127(62.0)$ \\
\hline Below average & $269(8.4)$ & $86(6.8)$ & $33(16.1)$ \\
\hline \multicolumn{4}{|l|}{ Family relationship* } \\
\hline Above average & $2501(78.5)$ & $1063(84.3)$ & $115(56.1)$ \\
\hline Average & $502(15.8)$ & 155 (12.3) & $46(22.4)$ \\
\hline Below average & $183(5.7)$ & $43(3.4)$ & $44(21.5)$ \\
\hline \multicolumn{4}{|l|}{ Parental caring* } \\
\hline Satisfied with father or mother & $545(17.1)$ & $184(14.6)$ & $58(28.3)$ \\
\hline Satisfied with both of them & $2471(77.6)$ & 1029 (81.6) & $118(57.6)$ \\
\hline Dissatisfied with both of them & $170(5.3)$ & $48(3.8)$ & $29(14.1)$ \\
\hline \multicolumn{4}{|l|}{ Academic achievement } \\
\hline Above average & $1361(42.7)$ & $558(44.3)$ & $84(41.0)$ \\
\hline Average & 932 (29.3) & $362(28.7)$ & $59(28.8)$ \\
\hline Below average & $893(28.0)$ & $341(27.0)$ & $62(30.2)$ \\
\hline \multicolumn{4}{|l|}{ Academic pressure* } \\
\hline Above average & $1344(42.2)$ & $399(31.6)$ & $137(66.8)$ \\
\hline Average & $1376(43.2)$ & $625(49.6)$ & 49 (23.9) \\
\hline Below average & $466(14.4)$ & $237(18.8)$ & $19(9.3)$ \\
\hline \multicolumn{4}{|l|}{ Relationship with teachers $†$} \\
\hline Good & $1552(48.7)$ & $694(55.0)$ & 69 (33.7) \\
\hline Average & $1408(44.2)$ & $493(39.1)$ & 95 (46.3) \\
\hline Poor & $226(7.1)$ & $74(5.9)$ & $41(20.0)$ \\
\hline \multicolumn{4}{|l|}{ Relationship with classmates* } \\
\hline Good & $2220(69.7)$ & $928(73.6)$ & 94 (45.9) \\
\hline Average & $846(26.6)$ & $289(22.9)$ & 79 (38.5) \\
\hline Poor & $120(3.8)$ & $44(3.5)$ & 32 (15.6) \\
\hline \multicolumn{4}{|l|}{ Feel lonely* } \\
\hline Less than 1 day/week & $1733(54.4)$ & $830(65.8)$ & $34(16.6)$ \\
\hline 1 to 4 days/week & $1073(33.7)$ & $335(26.6)$ & $98(47.8)$ \\
\hline More than 4 days/week & $380(11.9)$ & $96(7.6)$ & $73(35.6)$ \\
\hline \multicolumn{4}{|l|}{ Suicide ideation* } \\
\hline Never & 2589 (81.3) & $1108(87.9)$ & $88(42.9)$ \\
\hline Occasionally (1-2 times/year) & 391 (12.3) & $88(7.0)$ & $68(33.2)$ \\
\hline Sometimes (3-6 times/year) & $75(2.4)$ & $12(1.0)$ & $18(8.8)$ \\
\hline Often (over 6 times/year) & $131(4.1)$ & $53(4.2)$ & $31(15.1)$ \\
\hline \multicolumn{4}{|l|}{ Suicide attempt ${ }^{*}$} \\
\hline Never & $3083(95.8)$ & $1223(97.0)$ & $169(82.4)$ \\
\hline Occasionally (1-2 times/year) & $81(2.5)$ & $17(1.3)$ & $20(9.8)$ \\
\hline Sometimes (3-6 times/year) & $14(0.4)$ & $4(0.3)$ & $3(1.5)$ \\
\hline Often (over 6 times/year) & $38(1.2)$ & $17(1.3)$ & $13(6.3)$ \\
\hline
\end{tabular}


Table 2 Continued

\begin{tabular}{lccc}
\hline Variable & Total & With sleep disturbance & With depressive symptoms \\
\hline Hurt themselves on purpose* & $2807(88.1)$ & $1147(91.0)$ & $140(68.3)$ \\
Never & $269(8.4)$ & $78(6.2)$ & $43(21.0)$ \\
Occasionally (1-2 times/year) & $61(1.9)$ & $20(1.6)$ & $7(3.4)$ \\
Sometimes (3-6 times/year) & $49(1.5)$ & $16(1.3)$ & $15(7.3)$ \\
Often (over 6 times/year) & & & $79(38.5)$ \\
Running away from home* & $2262(71.0)$ & $1006(79.8)$ & $103(50.2)$ \\
Never & $815(25.6)$ & $226(17.9)$ & $6(2.9)$ \\
Considered & $48(1.5)$ & $14(1.1)$ & $17(8.3)$ \\
Planned & $61(1.9)$ & $15(1.2)$ & - \\
Attempted & $205(6.4)$ & $29(2.3)$ & - \\
Depressive symptoms $\dagger$ & $2981(93.6)$ & $1232(97.7)$ & $29(14.1)$ \\
Yes & $1261(39.6)$ & - & $176(85.9)$ \\
No & $1925(60.4)$ & - & \\
Sleep disturbance & &
\end{tabular}

competence were risk factors for sleep problems, ${ }^{6}$ and a study in Switzerland also documented the relationship between sleep disturbance in adolescents and family functioning and demonstrated that the mother's and adolescent children's sleep and well-being are particularly strongly correlated with each other. ${ }^{33}$ Furthermore, prior studies also demonstrated that suicide completers had higher rates of overall sleep disturbance among adolescents, ${ }^{34}$ and running away from home was as common as suicide completion among adolescents with depressive symptoms. ${ }^{35}$ Notably, our results also indicate that students with average or below-average academic pressure compared with above-average academic pressure were less likely to be troubled by sleep disturbance. This indicates that academic pressure is an important type of stress that affects sleep, and other studies have provided evidence that stress is associated with sleep disturbance. $^{36}$

Consistent with our expectation, adolescents who had depressive symptoms were at a higher risk for sleep disturbance. $\mathrm{Xu}$ et $a l^{12}$ has detected an association between sleep disturbance and depressive symptoms among Chinese adolescents. We found that sleep disturbance was common among adolescents in China, and an adolescent's family, school and psychosocial factors have influences on sleep disturbance. Thus, educational campaigns directed at families and schools are needed to improve awareness of the adverse consequence of sleep disturbance.

In this study, the prevalence of students with depressive symptoms was $6.4 \%$, slightly lower than the $8 \%$ reported in an Australian study. ${ }^{22}$ Depressive symptoms are a prevalent and disabling condition among adolescents that result in emotional suffering and sleep disturbance; therefore, it is important for us to focus on this problem. ${ }^{37}$ Our study reports that the prevalence of depressive symptoms among girls was not much higher than among boys, but a previous study reported prevalence rates of emotional problems to be higher in boys than in girls. ${ }^{38}$ These differences may due to emotional problems, including depressive symptoms and others. Additionally, our multivariate logistic regression showed that below-average family relationship, average or below-average relationships with classmates, emotional problems (including feeling lonely more than 1 day per week, having suicide ideations, considering running away from home) and having sleep disturbance was a risk factor for having depressive symptoms. Given that depressive symptoms are a type of emotional problem, ${ }^{39}$ it is not surprising that our results indicate a link between sleep disturbance and emotional problems. Consistent with the third hypothesis, our results clearly showed a link between sleep disturbance and depressive symptoms. However, the direction of the link was difficult to determine due to the nature of this crosssectional study; they might mutually reinforce each other, thereby formulating a vicious circle.

Given adolescents' vulnerability to sleep disturbance and depressive symptoms, we conducted this large-scale study aimed to investigate the prevalence and correlates of both problems in Chinese adolescents. To date, no research has expressly considered comprehensively the correlates of sleep disturbance and depressive symptoms among demographics, school, family and psychosocial domains in this population. Additionally, it must be stressed that there are several limitations to the current large-scale study. First, the data are crosssectional, so no causal inference can be made regarding the observed relationships between sleep disturbance and depressive symptoms, and the common-method 
Table 3 Adjusted OR $(95 \% \mathrm{Cl})$ for sleep disturbance by multilevel logistic regression

\begin{tabular}{|c|c|c|}
\hline Covariate & $\begin{array}{l}\text { Adjusted OR } \\
(95 \% \mathrm{Cl})\end{array}$ & p Value \\
\hline \multicolumn{3}{|l|}{ Age (years) } \\
\hline $13-14$ & 1.00 (reference) & \\
\hline $15-16$ & 2.40 (1.87 to3.08) & $<0.001$ \\
\hline $17-18$ & $1.36(1.15$ to 1.62$)$ & $<0.001$ \\
\hline \multicolumn{3}{|l|}{ Gender } \\
\hline Male & 1.00 (reference) & \\
\hline Female & $1.27(1.08$ to 1.48$)$ & 0.003 \\
\hline \multicolumn{3}{|l|}{ Habit of sleeping after lunch } \\
\hline Never & 1.00 (reference) & \\
\hline $\begin{array}{l}\text { Occasionally (1-4 } \\
\text { times/week) }\end{array}$ & 1.68 (1.27 to 2.22$)$ & $<0.001$ \\
\hline Often (over 4 times/week) & $1.05(0.89$ to 1.23$)$ & 0.590 \\
\hline \multicolumn{3}{|l|}{ Family relationship } \\
\hline Above average & 1.00 (reference) & \\
\hline Average & $1.08(0.71$ to 1.64$)$ & 0.723 \\
\hline Below average & 1.54 (1.06 to 2.26$)$ & 0.025 \\
\hline \multicolumn{3}{|l|}{ Academic pressure } \\
\hline Above average & 1.00 (reference) & \\
\hline Average & $0.80(0.65$ to 0.99$)$ & $<0.001$ \\
\hline Below average & 0.41 (0.33 to 0.51$)$ & $<0.001$ \\
\hline \multicolumn{3}{|l|}{ Relationship with teachers } \\
\hline Good & 1.00 (reference) & \\
\hline Average & $0.79(0.57$ to 1.11$)$ & 0.174 \\
\hline Poor & 1.26 (1.19 to 1.77$)$ & $<0.001$ \\
\hline \multicolumn{3}{|l|}{ Feel lonely } \\
\hline Less than 1 day/week & 1.00 (reference) & \\
\hline 1 to 4 days/week & 1.64 (1.39 to 1.94$)$ & $<0.001$ \\
\hline More than 4 days/week & 2.22 (1.70 to 2.89$)$ & $<0.001$ \\
\hline \multicolumn{3}{|l|}{ Suicide ideation } \\
\hline Never & 1.00 (reference) & \\
\hline $\begin{array}{l}\text { Occasionally (1-2 } \\
\text { times/year) }\end{array}$ & 1.78 (1.36 to 2.34$)$ & $<0.001$ \\
\hline Sometimes (3-6 times/year) & $2.37(1.25$ to 4.54$)$ & 0.009 \\
\hline Often (over 6 times/year) & 0.80 (0.54 to 1.20$)$ & 0.280 \\
\hline \multicolumn{3}{|l|}{ Running away from home } \\
\hline Never & 1.00 (reference) & \\
\hline Considered & $1.76(1.46$ to 2.13$)$ & $<0.001$ \\
\hline Planned & $1.42(0.74$ to 2.73$)$ & 0.298 \\
\hline Attempted & 2.59 (1.38 to 4.88$)$ & 0.003 \\
\hline \multicolumn{3}{|l|}{ Depressive symptoms } \\
\hline No & 1.00 (reference) & \\
\hline Yes & $2.47(1.61$ to 3.79$)$ & $<0.001$ \\
\hline
\end{tabular}

Adjusted OR means OR adjusted by multivariate analysis for screening risk factors for adolescents with sleep disturbance.

variance interpretation for the findings might apply. Second, the questionnaires did not include items that could address students with sleep-related breathing problems or psychological diseases such as attention-deficit hyperactivity disorder. Third, it should be noted that the present results that were based on a structured self-rating questionnaire were cross-sectional and retrospective; although self-reporting is a common and accepted method, we could not completely rule out the possibility of recall bias. To minimise incorrect or unavailable data given by students who did not fully understand the
Table 4 Adjusted OR (95\% Cl) for depressive symptoms by multilevel logistic regression

\begin{tabular}{|c|c|c|}
\hline Covariate & $\begin{array}{l}\text { Adjusted OR } \\
(95 \% \mathrm{Cl})\end{array}$ & p Value \\
\hline \multicolumn{3}{|l|}{ Family relationship } \\
\hline Above average & 1.00 (reference) & \\
\hline Average & $1.22(0.82$ to 1.81$)$ & 0.329 \\
\hline Below average & 1.97 (1.24 to 3.15$)$ & 0.004 \\
\hline \multicolumn{3}{|l|}{ Relationship with classmates } \\
\hline Good & 1.00 (reference) & \\
\hline Average & $2.82(1.62$ to 4.90$)$ & $<0.001$ \\
\hline Poor & $1.60(1.14$ to 2.25$)$ & 0.007 \\
\hline \multicolumn{3}{|l|}{ Feel lonely } \\
\hline Less than 1 day/week & 1.00 (reference) & \\
\hline 1 to 4 days/week & 2.67 (1.75 to 4.07$)$ & $<0.001$ \\
\hline More than 4 days/week & 4.24 (2.65 to 6.80$)$ & $<0.001$ \\
\hline \multicolumn{3}{|l|}{ Suicide ideation } \\
\hline Never & 1.00 (reference) & \\
\hline $\begin{array}{l}\text { Occasionally (1-2 } \\
\text { times/year) }\end{array}$ & $2.72(1.85$ to 3.98$)$ & $<0.001$ \\
\hline $\begin{array}{l}\text { Sometimes (3-6 } \\
\text { times/year) }\end{array}$ & 2.77 (1.46 to 5.26$)$ & 0.002 \\
\hline Often (over 6 times/year) & 3.38 (1.89 to 6.04$)$ & $<0.001$ \\
\hline \multicolumn{3}{|l|}{ Running away from home } \\
\hline Never & 1.00 (reference) & \\
\hline Considered & $1.71(1.20$ to 2.44$)$ & 0.003 \\
\hline Planned & 1.08 (0.40 to 2.90$)$ & 0.885 \\
\hline Attempted & $1.42(0.65$ to 3.10$)$ & 0.386 \\
\hline \multicolumn{3}{|l|}{ Sleep disturbance } \\
\hline No & 1.00 (reference) & \\
\hline Yes & 2.52 (1.64 to 3.86$)$ & $<0.001$ \\
\hline
\end{tabular}

Adjusted OR means OR adjusted by multivariate analysis for screening risk factors for adolescents showing depressive symptoms.

contents of the PSQI and the CES-D, we have provided a detailed explanation of the PSQI and CES-D.

In conclusion, the prevalence and correlates of sleep disturbances and depressive symptoms among adolescents in China are high, and further research into their causes, effects and remedies is warranted. The prevalence of sleep disturbance observed in this study suggests the importance of research on preventive interventions targeting sleep quality among Chinese students. Effective preventive measures require full consideration of the social and environmental factors. We should focus on the high-risk population whose family factors, school factors and psychosocial adjustments are negative.

Author affiliations

${ }^{1}$ Department of Medical statistics and Epidemiology, School of Public Health, Sun Yat-sen University, Guangzhou, People's Republic of China

${ }^{2}$ Center for ADR monitoring of Guangdong, Guangzhou, People's Republic of China

Acknowledgements The authors gratefully acknowledge the contribution of the Guangdong Education Bureau and its participating schools. The authors also thank the local health professionals, principals and teachers of participating schools. We express great thanks to all participants of our study. Contributors LG and CYL searched the literature, conceived the study, designed the study, analysed the data, interpreted the results, and drafted the 
report. JXD and $\mathrm{YH}$ organised the study, collected the data and analysed the data. XQD, JHH, GLH, XG collected the data, interpreted the results and obtained funding.

Funding This study was supported by the Guangdong Food and Drug Administration

Competing interests None.

Provenance and peer review Not commissioned; externally peer reviewed.

Data sharing statement No additional data are available.

Open Access This is an Open Access article distributed in accordance with the Creative Commons Attribution Non Commercial (CC BY-NC 4.0) license, which permits others to distribute, remix, adapt, build upon this work noncommercially, and license their derivative works on different terms, provided the original work is properly cited and the use is non-commercial. See: http:// creativecommons.org/licenses/by-nc/4.0/

\section{REFERENCES}

1. Crockett LJ, Beal SJ. The life course in the making: gender and the development of adolescents' expected timing of adult role transitions. Dev Psychol 2012;48:1727-38.

2. Anders TF, Eiben LA. Pediatric sleep disorders: a review of the past 10years. J Am Acad Child Adolesc Psychiatry 1997;36:9-20.

3. Lazaratou H, Dikeos DG, Anagnostopoulos DC, et al. Sleep problems in adolescence. A study of senior high school students in Greece. Eur Child Adolesc Psychiatry 2005;14:237-43.

4. Bailly D, Bailly-Lambin I, Querleu D, et al. [Sleep in adolescents and its disorders. A survey in schools]. Encephale 2004;30:352-9.

5. Garcia-Jimenez MA, Salcedo-Aguilar F, Rodriguez-Almonacid FM, et al. [The prevalence of sleep disorders among adolescents in Cuenca, Spain]. Rev Neurol 2004;39:18-24.

6. Liu X, Uchiyama M, Okawa M, et al. Prevalence and correlates of self-reported sleep problems among Chinese adolescents. Sleep 2000;23:27-34.

7. Association. AP. Diagnositic and statistical manual of mental disorders DSM IV. Washington, DC: American Psychiatric Association, 1994.

8. Pigeon WR, Cerulli $\mathrm{C}$, Richards $\mathrm{H}$, et al. Sleep disturbances and their association with mental health among women exposed to intimate partner violence. J Womens Health (Larchmt) 2011;20:1923-9.

9. Roane BM, Taylor DJ. Adolescent insomnia as a risk factor for early adult depression and substance abuse. Sleep 2008;31:1351-6.

10. Alfano CA, Zakem AH, Costa NM, et al. Sleep problems and their relation to cognitive factors, anxiety, and depressive symptoms in children and adolescents. Depress Anxiety 2009;26:503-12.

11. Roehr B. American Psychiatric Association explains DSM-5. BMJ 2013;346:f3591

12. Xu Z, Su H, Zou Y, et al. Sleep quality of Chinese adolescents: distribution and its associated factors. $J$ Paediatr Child Health 2012;48:138-45.

13. Stores G. Children's sleep disorders: modern approaches, developmental effects, and children at special risk. Dev Med Child Neurol 1999;41:568-73.

14. Chung KF, Cheung MM. Sleep-wake patterns and sleep disturbance among Hong Kong Chinese adolescents. Sleep 2008;31:185-94.

15. Abdel-Khalek AM. Prevalence of reported insomnia and its consequences in a survey of 5,044 adolescents in Kuwait. Sleep 2004:27:726-31.

16. Ohida T, Osaki Y, Doi Y, et al. An epidemiologic study of self-reported sleep problems among Japanese adolescents. Sleep 2004:27:978-85.
17. Liu X, Zhao Z, Jia C, et al. Sleep patterns and problems among chinese adolescents. Pediatrics 2008;121:1165-73.

18. Bajoghli H, Alipouri A, Holsboer-Trachsler E, et al. Sleep patterns and psychological functioning in families in northeastern Iran; evidence for similarities between adolescent children and their parents. J Adolesc 2013;36:1103-13.

19. Li SH, Shen XM, Jin XM, et al. [Sleep habits and sleep disturbance in school-age children of China]. Zhonghua Er Ke Za Zhi 2008;46:185-9.

20. Gong J, Li Y, Xg C, et al. [A baseline survey on the association of smoking onset and life events on adolescents in Wuhan, China] Zhonghua Liu Xing Bing Xue Za Zhi 2004;25:142-5.

21. Rona RJ, Li L, Gulliford MC, et al. Disturbed sleep: effects of sociocultural factors and illness. Arch Dis Child 1998;78:20-5.

22. Tsai PS, Wang SY, Wang MY, et al. Psychometric evaluation of the Chinese version of the Pittsburgh Sleep Quality Index (CPSQI) in primary insomnia and control subjects. Qual Life Res 2005;14:1943-52.

23. Buysse DJ, Reynolds CR, Monk TH, et al. The Pittsburgh Sleep Quality Index: a new instrument for psychiatric practice and research. Psychiatry Res 1989;28:193-213.

24. Myers JK, Weissman MM. Use of a self-report symptom scale to detect depression in a community sample. Am J Psychiatry 1980;137:1081-4

25. Cheng $\mathrm{CP}$, Yen $\mathrm{CF}, \mathrm{Ko} \mathrm{CH}$, et al. Factor structure of the Center for Epidemiologic Studies Depression Scale in Taiwanese adolescents. Compr Psychiatry 2012;53:299-307.

26. Lee SW, Stewart SM, Byrne BM, et al. Factor structure of the Center for Epidemiological Studies Depression Scale in Hong Kong adolescents. J Pers Assess 2008;90:175-84.

27. Zhang Jie WZFG. Development of the Chinese age norms of CES-D in urban area. Chin Ment Health J (In Chinese) 2010(02):139-43.

28. Yen S, Robins CJ, Lin N. A cross-cultural comparison of depressive symptom manifestation: China and the United States. J Consult Clin Psychol 2000;68:993-9.

29. Radloff LS, ed. The CES-D scale: A self-report depression scale for research in the general populations. Applied Psychological Measurement. 1977;1:385-401.

30. Meltzer LJ, Avis KT, Biggs S, et al. The Children's Report of Sleep Patterns (CRSP): a self-report measure of sleep for school-aged children. J Clin Sleep Med 2013;9:235-45.

31. Yang L, Zuo C, Eaton LF. Research note: sleep problems of normal Chinese adolescents. J Child Psychol Psychiatry 1987;28:167-72.

32. Kahn M, Sheppes G, Sadeh A. Sleep and emotions: bidirectional links and underlying mechanisms. Int J Psychophysiol 2013;89:218-28.

33. Kalak N, Gerber M, Kirov R, et al. The relation of objective sleep patterns, depressive symptoms, and sleep disturbances in adolescent children and their parents: a sleep-EEG study with 47 families. J Psychiatr Res 2012;46:1374-82.

34. Goldstein TR, Bridge JA, Brent DA. Sleep disturbance preceding completed suicide in adolescents. J Consult Clin Psychol 2008;76:84-91.

35. Tucker JS, Edelen MO, Ellickson PL, et al. Running away from home: a longitudinal study of adolescent risk factors and young adult outcomes. J Youth Adolesc 2011;40:507-18.

36. Byars KC, Yeomans-Maldonado G, Noll JG. Parental functioning and pediatric sleep disturbance: an examination of factors associated with parenting stress in children clinically referred for evaluation of insomnia. Sleep Med 2011:12:898-905.

37. Ivanenko A, Crabtree VM, Gozal D. Sleep and depression in children and adolescents. Sleep Med Rev 2005;9:115-29.

38. Liu X, Kurita H, Guo C, et al. Prevalence and risk factors of behaviora and emotional problems among Chinese children aged 6 through 11years. J Am Acad Child Adolesc Psychiatry 1999;38:708-15.

39. Siegel JM, Platt JJ, Peizer SB. Emotional and social real-life problem-solving thinking in adolescent and adult psychiatric patients. J Clin Psychol 1976;32:230-2. 